\title{
Treatment Options for the Adolescent Patient Experiencing Abnormal Uterine Bleeding
}

Rachael L. Polis, DO*

S. Paige Hertweck, MD

Address

*Kosair Children's Hospital, 3991 Dutchmans Lane, Suite 303, Louisville, KY, 40207, USA

Email: RLeighPolis@gmail.com

Published online: 8 July 2016

(C) Springer International Publishing AG 2016

This article is part of the Topical Collection on Pediatric Gynecology

Keywords Adolescent · AUB · PALM-COEIN • Menstruation · Treatment

\section{Opinion statement}

Abnormal uterine bleeding (AUB) is one of the most common reasons adolescent patients present for gynecologic care. A new classification system has been created to provide a universally accepted system of nomenclature to describe uterine bleeding causes in reproductive-aged women. The acronym PALM-COEIN (polyp, adenomyosis, leiomyoma, malignancy and hyperplasia, coagulopathy, ovulatory dysfunction, endometrial, iatrogenic and not yet classified) was introduced in 2011. This classification will help to target not only treatment but also future research into treatment options in the AUB population. In order for treatments to be effective, an accurate diagnosis is paramount. Adolescents tend to have anovulatory, infectious, or pregnancy-related causes of AUB. Traditional treatment modalities have been hormonal in nature, the most common being the use of oral contraceptive pills. The latest development has been the recognition of the effective use of the levonorgestrel intrauterine systems (LNG-IUS) in successful treatment of AUB in the adolescent population.

\section{Introduction}

Abnormal uterine bleeding (AUB) is one of the most common reasons that adolescent females present for gynecologic care. The underlying diagnosis is important in determining a treatment plan. 
In 2011, the International Federation of Gynecology and Obstetricians (FIGO) published a classification system for abnormal uterine bleeding known as PALM-COEIN [1]. The system was also adopted by the American College of Obstetricians and Gynecologists [2]. The system is comprised of four categories defined by structural entities, which can be measured with imaging techniques or via histopathology (PALM: polyp, adenomyosis, leiomyoma, and malignancy and hyperplasia). Structural abnormalities such as polyps, adenomyosis, and leiomyomas are uncommon in the adolescent patient however are possible and should remain in the differential diagnosis. Cervical polyps in the adolescent, while rare, have been reported in the literature [3].

The remaining acronym is defined as nonstructural and is unrelated to histopathology or imaging (COEIN: coagulopathy, ovulatory dysfunction, endometrial, iatrogenic, and not yet classified) [1]. The etiology of adolescents' causes of abnormal uterine bleeding will primarily present as a result of these nonstructural causes (COEIN). See Table 1.

The most common cause of AUB in the adolescent is anovulation [4]. Anovulation can result from abnormalities at any levels of the hypothalamic-pituitary-ovarian (HPO) axis resulting in the interruption of ovulation [4]. The most common causes of anovulation in the adolescent include immaturity of the HPO axis, hypothalamic hypogonadism, and polycystic ovarian syndrome.

The second most common cause of AUB in adolescents is coagulopathy [5-7]. Patients with heavy menstrual bleeding should be evaluated for both inherited and acquired disorders of coagulation [8]. Platelet dysfunction has been noted to be the most common hemostatic defect found in adolescents with AUB [9-12, 13•].

Von Willebrand disease is the most common inherited bleeding disorder among American women [8] and may present in the adolescent as AUB. The possibility of an underlying hematologic disorder in adolescents should be considered when they present with heavy menses and a hemoglobin level below $10 \mathrm{~g} / \mathrm{dL}$. This presentation should warrant a detailed hematologic investigation [14, 15]. Despite guidelines to screen for von Willebrand and other bleeding disorders in adolescents with heavy menses, a recent study determined that less than $25 \%$ of adolescents were screened [15].

Additional causes of AUB that would be more likely in an adolescent include pregnancy, sexually transmitted infections [16], and sexual trauma. Therefore, patients should also be questioned about sexual history and a part of their evaluation should include pregnancy testing, an appropriate physical examination, screening for chlamydia and gonorrhea as well as a hematologic evaluation. Similarly, a review of current medications should be completed as a

Table 1. Differential diagnosis for nonstructural causes of abnormal uterine bleeding in the adolescent (COEIN)

\begin{tabular}{|c|c|c|c|c|}
\hline Coagulopathy & $\begin{array}{l}\text { Ovulatory } \\
\text { dysfunction }\end{array}$ & Endometrial & Iatrogenic & $\begin{array}{l}\text { Not yet } \\
\text { classified }\end{array}$ \\
\hline $\begin{array}{l}\text { Platelet function } \\
\text { disorder }\end{array}$ & Anovulatory bleeding & Endometritis & $\begin{array}{l}\text { Breakthrough bleeding } \\
\text { (hormonal contraception- } \\
\text { LNG-IUS, hormonal } \\
\text { implant, depo } \\
\text { medroxyprogesterone) }\end{array}$ & Trauma \\
\hline $\begin{array}{l}\text { Von Willebrand } \\
\text { disease }\end{array}$ & $\begin{array}{l}\text { Polycystic ovarian } \\
\text { syndrome (PCOS) }\end{array}$ & $\begin{array}{l}\text { Infection (chlamydia, } \\
\text { gonorrhea, pelvic } \\
\text { inflammatory disease) }\end{array}$ & & Foreign body \\
\hline $\begin{array}{l}\text { Clotting factor } \\
\text { deficiency }\end{array}$ & Thyroid disease & & & \\
\hline Thrombocytopenia & Other & & & \\
\hline Anticoagulants & & & & \\
\hline
\end{tabular}


common side effect of contraceptive medications (use of continuous oral contraceptive pills, subdermal implant, levonorgestrel intrauterine device) can be breakthrough bleeding perceived as AUB.

\section{Treatment}

The initial management of AUB in the adolescent is based on whether the AUB is acute or chronic. In cases of acute AUB, the patient's hemodynamic stability and identification of the underlying cause of bleeding will determine management $[17 \bullet]$. The proceeding medical management will also be based on the etiology and the severity of the patient's anemia. Surgical interventions are rare in the adolescent, as most patients improve with medical treatment. Treatment goals include cessation of current bleeding, prevention of worsening anemia, improvement of an adolescent's quality of life, and the establishment of a regular menstrual cycle [17•]. As hormonal methods of treatment are commonly used to treat AUB, prior to their use, it is important to rule out any contraindication by obtaining a complete personal and family history and consulting the Centers for Disease and Control and Prevention's Medical Eligibility Criteria for Contraceptive Use [18], the World Health Organization for published criteria on contraceptive use [19], and the U.S. Food and Drug Administration labeling information website [20]. This is particularly important in that many of these adolescents may require both the contraceptive efficacy of the treatment in addition to the hormonal treatment of AUB. Chronic AUB occurs when uterine bleeding is abnormal in volume, regularity, and/or timing and has occurred for most of the past 6 months. Unlike acute AUB, which requires immediate intervention, chronic AUB does not [1].

\section{Pharmacologic treatment}

\section{Hormonal}

\section{Combination estrogen and progestin-containing contraceptives}

The goal of medical therapy in acute AUB is to stabilize the endometrium with estrogen to provide initial hemostasis with the addition of progestins for endometrial stability. Combination oral contraceptive pills (COCP) taken continuously for several months stop menstruation and allow patients to regain their hemodynamic stability [17•]. COCP is cost effective as most pills are also found in generic formulations. Mention of brand names does not imply endorsement of particular products.

Lo Ovral ${ }^{\circledR}$ (Akrimax Pharmaceuticals LLC, Cranford, NJ) is a monophasic combination contraceptive containing $0.3 \mathrm{mg}$ norgestrel and $30 \mathrm{mcg}$ ethinyl estradiol. For severe bleeding with a moderate hemoglobin level (Hgb 8-10 g/ $\mathrm{dL}$ ), COCP taper can be initiated [21]. A commonly used taper dose would be one tablet by mouth every $6 \mathrm{~h}$ for 2 days, followed by one tablet every $8 \mathrm{~h}$ for 2 days, then one tablet every $12 \mathrm{~h}$ for 2 days, and continue to take one tablet daily skipping placebo pills and starting a new pack with active pills. If bleeding resumes as the tapering dose is decreased, one can increase pills to a dose of twice daily until completing the 21-day cycle [21]. Patients may often 
experience nausea with increased dosages of estrogen, and therefore, an antiemetic can be administered before the patient receives the dose of oral contraceptive.

Patients with severe anemia (Hgb $\leq 7 \mathrm{~g} / \mathrm{dL}$ ) or moderate anemia (Hgb 8$10 \mathrm{~g} / \mathrm{dL}$ ) with active bleeding may often need to be hospitalized if hemodynamically unstable. They can be treated with a similar COCP taper but may require one tablet every 4 to $6 \mathrm{~h}$ until bleeding decreases. This can take up to 24-36 h. Upon significant decrease of bleeding, the pill taper can be decreased to one pill three times a day for 3 days and then one pill twice a day until hematocrit is above $30 \%$ [21].

Intravenous or intramuscular estrogen is rarely indicated in patients experiencing acute AUB and is used primarily when patients are unable to tolerate oral medications or continuous bleeding results despite maximum oral therapy. Conjugated estrogens, Premarin ${ }^{\circledR} 25$ mg (Wyeth Pharmaceuticals Inc, Philadelphia, PA), can be administered intravenously every $4-6 \mathrm{~h}$ for two or three doses as it has a proven indication for treatment for acute AUB. The use of estrogens has been associated with increased risk of a blood clot [21]. While estrogen will cause cessation of acute bleeding, it is important to add progestin therapy as re-bleeding from estrogen withdrawal can occur when IV estrogen is discontinued [21]. Many practitioners will address this issue by placing a patient on a COCP following cessation of bleeding with IV Premarin ${ }^{\circledR}$.

Use of continuous oral contraceptive pills (using the active pills continuously from a pack of 28-day oral contraceptives and discarding the inactive placebo pills) or an extended cycle of 84-day oral contraceptives such as Seasonale ${ }^{\circledR}$ (Teva Pharmaceuticals USA, Inc, Sellersville, PA), a monophasic combination contraceptive containing levonorgestrel $0.15 \mathrm{mg}$ and ethinyl estradiol $0.03 \mathrm{mg}$, can help anemic patients skip monthly menses.

Other options for extended or continuous regimens of hormonal therapy have been described in the adult population [22]. These include the use of the vaginal ring (NuvaRing ${ }^{\circledR}$, Merck \& Co., Inc., Whitehouse Station, NJ) containing $11.7 \mathrm{mg}$ etonogestrel/2.7 mg ethinyl estradiol or the 6-mg norelgetromin/0.75mg ethinyl estradiol transdermal contraceptive patch (Ortho Evra ${ }^{\circledR}$, Janssen Pharmaceuticals, Inc., Titusville, NJ). The ring may be used continuously by placing one ring monthly [23]. The ring can be removed for 4 days when breakthrough bleeding occurs and then re-inserted [23]. The extended patch cycle can consist of weekly patch use for 12 consecutive weeks followed by a patch-free week [24].

The traditional choice of treatment of heavy menstrual bleeding due to von Willebrand disease is COCP [25-27]. COCP have been found to reduce menstrual blood loss and increase hemoglobin concentrations in anemic women [25]. They can be administered continuously or in an extended regimen to reduce the frequency and severity of bleeding and control the timing of bleeding [28]. There are reports of successful treatment of AUB with COCP in conjunction with tranexamic acid [28]. However, clinicians should be aware that this combination is listed as a contraindication in the tranexamic prescribing information as of 2013 due to the potential risk of thromboembolic events [29].

Patients with contraindications for receiving estrogen due to a history of blood clots, uncontrolled chronic hypertension, migraines with aura, or specific chronic illnesses can be treated with alternative medications. COCP should also 
be used with careful consideration in adolescents who are immobile as they might be at increased risk for a blood clot.

The most common reason for chronic AUB in the adolescent is typically the result of anovulation associated with polycystic ovarian syndrome (PCOS). COCP suppress ovarian and adrenal androgen production and increase sex hormone-binding globulin resulting in improved symptoms of acne and hirsutism associated with PCOS. Treatment with 20-35 mcg of ethinyl estradiol remains common among anovulatory adolescents [4]. In addition to regulating menstrual cycles, COCPs can improve unwanted hair growth in 50 to $70 \%$ of women [30].

\section{Progesterone-only methods}

In those patients experiencing acute AUB who have contraindications to COCP, treatment with progesterone-only methods is an alternative. Norethindrone acetate (Aygestin ${ }^{\circledR}$, Teva Women's Health Inc, Sellersville, PA) can be administered as a taper taking 5 or $10 \mathrm{mg}$ orally four times a day for 4 days, three times a day for 3 days, and twice a day for 2 weeks [21]. Medroxyprogesterone acetate (Provera ${ }^{\circledR}$, Pfizer, New York, NY) 20 mg orally three times a day for a week can also be given to patients with acute vaginal bleeding [31]. Santos et al. noted the first use of a norethindrone $0.35 \mathrm{mg}$ taper to treat heavy bleeding episodes in the adolescent population (Ortho Micronor ${ }^{\circledR}$, Janssen Pharmaceuticals Inc., Titusville, NJ) [32•]. Two regimens of use were described: either taking one tablet of norethindrone $0.35 \mathrm{mg}$ twice daily for a week, followed by one tablet daily for 21 days, or one tablet taken three times daily for 3 days, followed by one tablet twice daily for a week and then taken daily [32•]. The most commonly noted side effects included irregular bleeding, nausea/vomiting, mood swings, and hot flashes. Discontinuation rates were high secondary to side effects of breakthrough bleeding [32•].

Progestins are also an option for adolescents who are experiencing anovulatory bleeding, without hirsutism or acne, and for whom contraception is not a concern. Progestins can be prescribed cyclically to induce a withdraw bleed [30] by prescribing Provera ${ }^{\circledR} 10 \mathrm{mg}$ orally for 10 days either monthly or every 3 months. For those patients who would prefer complete menstrual suppression or significantly decreased flow, a continuous progestin-only pill Ortho Micronor ${ }^{\circledR}$ or higher doses of Aygestin ${ }^{\circledR} 10$ to $15 \mathrm{mg}$ daily may be prescribed [30].

Medroxyprogesterone acetate $150 \mathrm{mg}$ injectable (Depot Provera ${ }^{\circledR}$, Pharmacia \&Upjohn Co, Division of Pfizer Inc, New York, NY) is administered intramuscularly every 12 weeks and has been used for treatment in AUB. While amenorrhea is associated with prolonged use [33], it occasionally results in irregular menstrual bleeding that many adolescents find bothersome and unacceptable. Depot Provera ${ }^{\circledR}$ users have been noted to have a decrease in bone mineral density when compared to normal menstruating controls [34, 35]. However, no highquality data is available to inform us whether the decrease in bone mineral density associated with use will affect eventual fracture risk in adolescents [35]. Depo Provera ${ }^{\circledR}$ may be a good option for temporary use in some patients. It should be used with caution in adolescents with immobility as they might already have a low baseline bone density for their age. Additionally, Depo Provera ${ }^{\circledR}$ use has been associated with increased weight gain which can be problematic for this population [36]. 


\section{Anti-inflammatory medications}

Individuals who experience mild bleeding (longer than normal periods or shortened menstrual cycles for more than 2 months) and have normal hemoglobin [21] may benefit from a nonsteroidal antiinflammatory (NSAID). A Cochrane review demonstrated NSAIDs are more effective than placebo at reducing menstrual blood loss in women with regular menstrual cycles. However, they were less effective than tranexamic acid, danazol, and the levonorgestrel-releasing intrauterine device (LNG-IUS) [37]. Studied dosages of naproxen (Naprosyn ${ }^{\circledR}$, Roche Laboratories Inc, Nutley, NJ) varied between 250 and $500 \mathrm{mg}$ twice a day or up to four times daily and ibuprofen regimens from 600 to $1200 \mathrm{mg}$ daily [37]. Patients with von Willebrand disease or other coagulation disorders should avoid NSAID products that prevent platelet adhesion as they may increase blood loss $[8,21]$.

\section{Antifibrinolytic agents}

Antifibrinolytic agents such as tranexamic acid (Lysteda ${ }^{\circledR}$, Ferring Pharmaceutics Inc, Parsippany, NJ, USA) are nonhormonal and noncontraceptive methods for women who experience heavy menstrual bleeding. This plasminogen activator inhibitor decreases fibrinolysis and promotes clot formation resulting in reduced menstrual blood loss. Antifibrinolytics cause a greater reduction of heavy menstrual bleeding when compared to placebo [38]. Lysteda is prescribed as $1300 \mathrm{mg}$ orally three times daily for a total of 5 days during monthly menses [29]. The most common side effects include headaches, backaches, nasal sinus problems, abdominal pain, nausea, and vomiting [29].

Contraindications include but are not limited to thrombotic or thromboembolic disease [31].

Lysteda ${ }^{\circledR}$ is not approved by the FDA for use in premenarcheal girls and is only indicated for women of reproductive age as its use was not originally studied in young women under the age of 18 . However, antifibrinolytics have been demonstrated to decrease menstrual blood loss in adolescents [28]. Srivaths et al. conducted a small pilot study comparing oral tranexamic acid to combination oral contraceptives for adolescents with heavy menstrual bleeding [39]. The results demonstrated tranexamic acid appeared to be as effective in the management of adolescent heavy menstrual bleeding in reducing menstrual blood loss and improving the participant's quality of life [39].

\section{Vasopressin analog}

Desmopressin acetate (DDAVP ${ }^{\circledR}$, Ferring Pharmaceuticals Inc, Parsippany, $\mathrm{NJ}$ ) is a synthetic analog of vasopressin that improves bleeding in patients with von Willebrand disease and decreases heavy menstrual bleeding. Kouides et al. conducted a prospective crossover study between intranasal desmopressin and oral tranexamic acid, which demonstrated 
that while both improved quality of life and reduced menstrual blood loss, tranexamic acid proved to be more effective [40]. A Cochrane review by Ray et al. compared nonsurgical interventions for treating heavy menstrual bleeding in women with bleeding disorders [41]. There is a paucity of data showing improvement of heavy menstrual bleeding with the use of desmopressin when compared to placebo [41].

Additional randomized controlled trials are needed. Patients who do opt to try desmopressin acetate require restrictions on their fluid intake secondary to the risk of hyponatremia. In the majority of cases, use of DDAVP ${ }^{\circledR}$ is reserved for those patients with a bleeding disorder who have been found to be DDAVP ${ }^{\circledR}$ responders and is typically prescribed and managed by a hematologist.

\section{Vitamins}

Patients with AUB and anemia should receive iron replacement therapy. No specific iron preparation is more effective than another. The target dosage is 150 to $200 \mathrm{mg} /$ day of elemental iron in one to three divided doses per day [42]. Iron should be taken on an empty stomach with orange juice to assist absorption. If the patient experiences severe anemia ( $\mathrm{Hgb} \leq 7 \mathrm{~g} / \mathrm{dL})$, they might benefit from folate or multivitamin supplementation [17•]. In patients who are intolerant of oral iron preparations and have heavy menstrual bleeding, IV iron therapy may be indicated [43]. Regardless of the iron preparation product used, IV iron therapy has been found to be effective and safe to increase hemoglobin levels to near normal with no serious adverse affects [43].

\section{Interventional procedures}

\section{Exam under anesthesia and dilatation and curettage (D\&C)}

In most cases of AUB, medical therapy is sufficient. In those patients for whom medical management does not decrease bleeding and in whom vital signs are unstable, surgical evaluation may be warranted with an exam under anesthesia. A D\&C can be both diagnostic and therapeutic but is rarely needed in the adolescent patient [21]. The risks of a D\&C procedure include anesthesia, uterine perforation, infection, and Ashermans syndrome (intrauterine adhesions).

\section{Foley catheter for mechanical tamponade}

Adolescents who fail medical treatment and have continued profuse bleeding might benefit from a mechanical measure to tamponade bleeding within the uterine cavity until medical treatments can be effective. After evacuation of clots from the uterine cavity, a 16- or 18French Foley catheter with a 30-cc balloon can be placed into the uterus [44]. Cervical dilation may be required to pass the catheter through the cervix. Once inside the uterine cavity, the balloon is inflated with saline until it is filled and bleeding stops. The positioning of the catheter can be confirmed by ultrasound and is kept in place for up to $24 \mathrm{~h}$. Foley catheters have been used to control postpartum hemorrhage [45], and 
information about their use has been extrapolated to the adolescent patient [44].

\section{Assistive devices}

Hormonal

\section{Levonorgestrel intrauterine system}

LNG-IUS is an excellent management option for a patient experiencing chronic abnormal uterine bleeding. A recent Cochrane review published in 2015 by Lethaby et al. concluded the LNG-IUS is more effective than oral medication (oral contraceptive pill, mefenamic acid, medroxyprogesterone acetate, norethindrone acetate) as a treatment for heavy menstrual bleeding and is associated with greater reduction in heavy menstrual bleeding and improvement in quality of life, and appears to be more acceptable long term. However, the LNGIUS is associated with more minor adverse effects than oral therapy [46•].

Mirena ${ }^{\circledR}$ (Bayer Healthcare Pharmaceuticals Inc., Whippany, NJ, USA), a 5-year intrauterine device (IUD), and Liletta ${ }^{\circledR}$ (Medicine360, San Francisco, CA, USA, and Actavis, Parsippany, NJ, USA, trademark of Odyssea Pharma SPRL [Belgium], an Actavis affiliate), a 3-year IUD, both contain $52 \mathrm{mg}$ of levonorgestrel. Not only is LNG-IUS a long-term management option for AUB in adolescents but it is also a highly effective contraception option in an at-risk population. The LNG-IUS has been found to be more effective at reducing menstrual blood loss with greater increases in hemoglobin and ferritin compared with other oral medical management [47-49]. It is a well-tolerated method for patients with heavy menses and in women with inherited bleeding disorders [50]. In adolescents with AUB secondary to anovulation, the LNG-IUS has been demonstrated to be effective and should be considered in all age groups [4].

LNG-IUS use has been noted to be more effective than medical treatment in reducing the effects heavy menstrual bleeding has on quality of life [51]. The 2-year continuation rates in women using the LNG-IUS are higher than in women receiving typical medical treatment for AUB [51]. A cohort study among adolescents in New Zealand using the LNG-IUS had a 1-year continuation rate of $85 \%$ [52]. A study in the UK also identified LNG-IUS as the most cost-effective treatment when using their quality-of-life measures to estimate the quality-adjusted life years (QALY) as a primary indicator of treatment success [53]. Sanghera et al. concluded using UK guidelines the LNG-IUS would be the recommended treatment for heavy menstrual bleeding [53].

Side effects of the LNG-IUS include pain with insertion, risk of expulsion, irregular bleeding or spotting, headaches, pelvic pain, breast tenderness, and ovarian cysts [46•]. Adolescents should also be advised that uterine size can preclude insertion. The Mirena ${ }^{\circledR}$ requires a uterine sound depth of $6 \mathrm{~cm}$ and the Liletta ${ }^{\circledR} 5.5 \mathrm{~cm}$. The presence of a uterine anomaly may also preclude insertion of an IUS. 
There is a smaller 3-year intrauterine system, $\mathrm{Skyla}^{\circledR}$, containing $13.5 \mathrm{mg}$ of levonorgestrel (Bayer Healthcare Pharmaceuticals Inc., Wayne, NJ), but there is no medical literature at this time regarding its use in treatment of AUB.

\section{Subdermal implant}

\section{Diet and lifestyle}

The 68-mg etonorgestrel subdermal implant is a rod placed subdermally in the arm for 3 years (Nexplanon ${ }^{\circledR}$, Merck \& Co Inc., Whitehouse Station, NJ). The subdermal implant is associated with an overall decrease in bleeding with continued use [54]. However, its use has not been described as a primary treatment for AUB. It is an effective long-term form of contraception for the adolescent patient. Users should be counseled about the side effect of unpredictable breakthrough bleeding. Patients also may report acne, headaches, mood swings, weight gain, and nausea.

\section{Exercise}

\section{Pediatric considerations}

Anovulation and therefore AUB can be associated with an increased body mass index. Exercise with associated weight loss may improve ovulatory function [4, $55,56]$ and therefore improve AUB. While diet and exercise education is an important adjunct to the medical management of these patients, most patients who present with AUB are in need of immediate treatment to manage their bleeding symptoms.

Clinicians in the care of young female patients need to be anticipatory in their management of menarche in patients with known bleeding disorders. A study by Dowlut-McElroy et al. identified prepubertal girls with known bleeding disorders who do not have a plan of care in the event they had heavy menstrual bleeding after menarche [6]. They conclude a consultation with a pediatric gynecologist or hematologist prior to menarche would be helpful to review abnormal bleeding patterns and discuss possible treatment options should they experience heavy menses. Adolescents with bleeding disorders should also be encouraged to wear medical alert bracelets [8]. Today, there are many fashionable medical jewelry options available including Lauren's Hope ${ }^{\circledR}$ Medical ID Jewelry [57] and American Medical ID ${ }^{\circledR}$ [58].

\section{Conclusion}

Over the past 5 years, AUB has a new classification system (PALM-COEIN) that should be used in the evaluation of AUB in all reproductive-aged women including the adolescent. This classification will help to define the cause of the bleeding and thereby target treatment. Adolescents more commonly have anovulatory bleeding, a bleeding disorder, infectious causes of bleeding, and potentially pregnancy-related bleeding. Awareness of this information should help the clinician to focus the history and physical examination. Traditionally, COCPs have been used to treat AUB in the adolescent but recent literature 
shows the advancement and success of the use of LNG-IUS, which may surpass the use of COCPs for treatment of AUB in this patient population in the future.

A recent study by Haguelet et al. demonstrated variations in strategies of treatment among pediatric subspecialties in treating adolescents with acute AUB and identified a lack of standardized care for adolescents [59]. Future evaluations of standardized management of AUB in adolescents would be helpful to identify the optimal treatment plan [59].

\section{Compliance with Ethical Standards}

\section{Conflict of Interest}

Rachael L. Polis declares that she has no conflict of interest. S. Paige Hertweck declares that she has no conflict of interest.

Human and Animal Rights and Informed Consent

This article does not contain any studies with human or animal subjects performed by any of the authors.

\section{References and Recommended Reading}

Papers of particular interest, published recently, have been highlighted as:

- Of importance

1. Munro MG, Critchley HO, Broder MS, Fraser IS. FIGO classification system (PALM-COEIN) for causes of abnormal uterine bleeding in nongravid women of reproductive age. Int J Gynecol Obstet. 2011;113:3-13.

2. Diagnosis of abnormal uterine bleeding in reproductive-aged women. Practice Bulletin No. 128. American College of Obstetricians and Gynecologists. Obstet Gynecol 2012; 120:197-206

3. Soyer T, Demirdag G, Gucer S, Orhan D, Karnak I. Giant cervical polyp with mesonephric duct remnants: unusual cause of vaginal bleeding in an adolescent girl. Fetal Pediatr Pathol. 2014;33:176-81.

4. Management of abnormal uterine bleeding associated with ovulatory dysfunction. Practice Bulletin No. 136. American College of Obstetricians and Gynecologists. Obstet Gynecol. 2013;122:176-185

5. Basaran HO, Akgul S, Oksuz-Kanbur N, Gumruk F, Cetin M, Derman O. Dysfunctional uterine bleeding in adolescent girls and evaluation of their response to treatment. Turk J Pediatr. 2013;55:186-9.

6. Dowlut-McElroy T, Williams KB, Carpenter SL, Strickland JL. Menstrual patterns and treatment of heavy menstrual bleeding in adolescents with bleeding disorders. J Pediatr Adolesc Gynecol. 2015;28:499501.

7. Kanbur NO, Derman O, Kutluk T, Gurgey A. Coagulation disorders as the cause of menorrhagia in adolescents. Int J Adolesc Med Health. 2004;16:183-5.
8. Von Willebrand disease in women. Committee Opinion No. 580. American College of Obstetricians and Gynecologists. Obstet Gynecol. 2013; 122:1368-1373

9. Amesse LS, Pfaff-Amesse T, Gunning WT, Duffy N, French JA. Clinical and laboratory characteristics of adolescents with platelet function disorders and heavy menstrual bleeding. Exp Hematol Oncol. 2013;2:3. doi:10.1186/2162-3619-2-3.

10. Vo KT, Grooms L, Klima J, Holland-Hall C, O'Brien SH. Menstrual bleeding patterns and prevalence of bleeding disorders in a multidisciplinary adolescent haematology clinic. Haemophilia. 2013;19:71-5.

11. Philipp CS, Dilley A, Miller CH, Evatt B, Baranwal A, Schwartz R, et al. Platelet defects in women with unexplained menorrhagia. J Thrombo Haemost. 2003;1:477-84.

12. Philipp CS, Faiz A, Dowling N, Dilley A, Michael LA, Ayers $\mathrm{C}$, et al. Age and the prevalence of bleeding disorders in women with menorrhagia. Obstet Gynecol. 2005; 105:61-6.

13. Seravalli V, Linari S, Peruzzi E, Dei M, Paladino E, Bruni $\mathrm{V}$. Prevalence of hemostatic disorders in adolescents with abnormal uterine bleeding. J Pediatr Adolesc Gynecol. 2013;26:285-9.

The study identified AUB in adolescents most frequently associated with an underlying bleeding disorder and the most common disorder of hemostasis was a platelet function disorder. 
14. Oral E, Cagas A, Gezer A, Kaleli S, Aygin Y, Ocer F. Hematological abnormalities in adolescent menorrhagia. Arch Gynecol Obstet. 2002;266:72-4.

15. Khamees D, Klima J, O'Brien SH. Population screening for Von Willebrand disease in adolescents with heavy menstrual bleeding. J Pediatr. 2015;166:195-7.

16. Toth M, Patton DL, Esquenzi B, Shevchuk M, Thaler H, Divon M. Association between Chlamydia trachomatis and abnormal uterine bleeding. Am J Reprod Immunol. 2007;57:361-6.

17. Bennett AR, Gray SH. What to do when she's bleeding through: the recognition, evaluation, and management of abnormal uterine bleeding in adolescents. Curr Opin Pediatr. 2014;26:413-9.

A thoughtful review in the evaluation and management of AUB in adolescents.

18. Centers for Disease Control and Prevention (CDC). US medical eligibility criteria for contraceptive use, 2010. MMWR. 2010;59(RR-04):1-85.

19. Medical eligibility criteria for contraceptive use. 5th edition. Geneva: World Health Organization; 2015.

20. Food and Drug Administration. FDA online label repository. Available at: http://labels.fda.gov. Retrieved December 25, 2015.

21. Gray SH, Emans SJ. Abnormal vaginal bleeding in the adolescent. In: Emans SJ, Laufer MR, editors. Emans, Laufer, Goldstein's pediatric adolescent gynecology. 6th ed. Philadelphia, PA: Lippincott; 2012. p. 159-67.

22. Jacobson JC, Likis FE, Murphy PA. Extended and continuous combined contraceptive regimens for menstrual suppression. J Midwifery Womens Health. 2012;57:585-92.

23. Sulak PJ, Smith V, Coffee A, Witt A, Kuehl AL, Kuehl TJ. Frequency and management of break through bleeding with continuous use of the transvaginal contraceptive ring. Obstet Gynecol. 2008;112:563-71.

24. Stewart FH, Kaunitz AM, LaGuardia KD, Karvois DL, Fisher AC, Friedman AJ. Extended use of a transdermal norelgestromin/ethinyl estradiol: a randomized trial. Obstet Gynecol. 2005;105:1389-96.

25. James AH. Von Willebrand disease. Obset Gynecol Surv. 2006;61:136-45.

26. James AH, Manco-Johnson MJ, Yawn BP, Dietrich JE, Nichols WL. Von Willebrand disease: key points from the 2008 National Heart, Lung, and Blood Institute guidelines. Obstet Gynecol. 2009;114:674-8.

27. Nichols WL, Hultin MB, James AH, Manco-Johnson MJ, Montgomery RR, Ortel TL, et al. von Willebrand disease (VWD): evidence-based diagnosis and management guidelines, the National Heart, Lung, and Blood Institute (NHLBI) expert panel report. Haemophilia. 2008;14:171-232.

28. Chi C, Pollard D, Tuddenham E, Kadir RA. Menorrhagia in adolescents with inherited bleeding disorders. J Pediatr Adolesc Gynecol. 2010;23:215-22.

29. Highlights of Prescribing Information. Lysteda.com website. http://www.lysteda.com/assets/pi_ferring20131f2d77bcb42b5738c55afab5280d7e9c.pdf. Updated October 2013. Accessed January 24, 2016.
30. DiVasta AD, Emans SJ. Androgen abnormalities in the adolescent girl. In: Emans SJ, Laufer MR, editors. Emans, Laufer, Goldstein's pediatric adolescent gynecology. 6th ed. Philadelphia, PA: Lippincott; 2012. p. 168-87.

31. Management of acute abnormal uterine bleeding in nonpregnant reproductive-aged women. Committee Opinion No. 557. American College of Obstetricians and Gynecologists. Obstet Gynecol 2013;121:891-896

32. Santos M, Hendry D, Sangi-Haghpeykar H, Dietrich JE. Retrospective review of norethindrone use in adolescents. J Pediatr Adolesc Gynecol. 2014;27:41-4.

First published study to address the use of a norethindrone taper for heavy bleeding episodes in the adolescent population.

33. Hubacher D, Lopez L, Steiner MJ, Dorflinger L. Menstrual pattern changes from levonorgestrel subdermal implants and DMPA: systemic review of evidence based comparisons. Contraception. 2009;80:113-8.

34. Lara-Torre E, Edwards CP, Perlman S, Hertweck SP. Bone mineral density in adolescent females using depo medroxyprogesterone acetate. J Pediatr Adolesc Gynecol. 2004; 17:17-21.

35. Depo medroxyprogesterone acetate and bone effects. Committee Opinion No. 602. American College of Obstetricians and Gynecologists. Obstet Gynecol 2014; 123:1398-1402

36. Menstrual manipulation for adolescents with disabilities. ACOG Committee Opinion No. 448. American College of Obstetricians and Gynecologists. Obstet Gynecol 2009; 114:1428-1431

37. Lethaby A, Duckitt K, Farquhar C. Non-steroidal antiinflammatory drugs for heavy menstrual bleeding. Cochrane Database Sys Rev. 2013;1, CD000400.

38. Lethaby A, Farquhar C, Cooke I. Antifibrinolytics for heavy menstrual bleeding. Cochrane Database Syst Rev 2000; CD000249.

39. Srivaths LV, Dietrich JE, Yee DL, Sangi-Haghpeykar H, Mahoney D. Oral tranexamic acid versus combination oral contraceptives for adolescent heavy menstrual bleeding: a pilot study. J Pediatr Adolesc Gynecol. 2015;28:254-7.

40. Kouides PA, Byams VR, Philipp CS, Stein SF, Heit JA, Lukes AS, et al. Multisite management study of menorrhagia with abnormal laboratory hemostasis: a prospective crossover study of intranasal desmopressin and oral tranexamic acid. Br J Haematol. 2009;145:212-20.

41. Ray S, Ray A. Non-surgical interventions for treating heavy menstrual bleeding (menorrhagia) in women with bleeding disorders. Cochrane Database Sys Rev. 2014;11, CD010338.

42. Rydz N, Jamieson MA. Managing heavy menstrual bleeding in adolescents. Contemporary OB/GYN. 2013;58:49-52.

43. Mantadakis E. Advances in pediatric intravenous iron therapy. Pediatr Blood Cancer. 2016;63:11-6.

44. Wilkinson JP, Kadir R. Management of abnormal uterine bleeding in adolescents. J Pediatr Adolesc Gynecol. 2010;23:S22-30. 
45. Post partum hemorrhage. ACOG Practice Bulletin No. 76. American College of Obstetricians and Gynecologists. Obstet Gynecol. 2006; 108:1039-1047

46. Lethaby A, Hussain M, Rishworth JR, Rees MC. Progesterone or progesterone-releasing intrauterine system for heavy menstrual bleeding. Cochrane Database Sys Rev. 2015;4:CD002126.

The Cochrane review identified the LNG IUS as more effective then oral medication in the treatment of heavy menstrual bleeding and is associated with greater reduction in heavy menstrual bleeding and improvement in quality of life.

47. Shabaan MM, Zakherah M, El-Nashar SA, Sayed GH. Levonorgestrel-releasing intrauterine system compared to low dose combined oral contraceptive pills for idiopathic menorrhagia: a randomized clinical trial. Contraception. 2011;83:48-54.

48. Kauntiz AM, Bissonnette F, Monteiro I, Lukkari-Lax E, Muysers C, Jensen JT. Levonorgestrel-releasing intrauterine system or medroxyprogesterone for heavy menstrual bleeding. Obstet Gynecol. 2010;116:62532.

49. Kaunitz AM, Bissonnette F, Monteiro I, Lukkari-Lax E, DeSanctis Y, Jensen J. Levonorgestrel-releasing intrauterine system for heavy menstrual bleeding improves hemoglobin and ferritin levels. Contraception. 2012;452-457.

50. Kingman CE, Kadir RA, Lee CA, Economides DL. The use of levonorgestrel-releasing intrauterine system for treatment of menorrhagia in women with inherited bleeding disorders. BJOG. 2004;111:1425-8.

51. Gupta J, Kai J, Middleton M, Pattison H, Gray R, Daniels J. Levonorgestrel intrauterine system versus medical therapy for menorrhagia. N Engl J Med. 2013;368:12837.

52. Paterson H, Ashton J, Harrison-Woolrych M. A nationwide cohort study of the new use of the levonogestrel intrauterine device in New Zealand adolescents. Contraception. 2009;79:433-8.

53. Sanghera S, Roberts TE, Barton P, Frew E, Daniels J, Middleton L, Gennard L, Kai J, Gupta JK.

Levonorgestrel-releasing intrauterine system vs. usual medical treatment for menorrhagia: an economic evaluation alongside a randomised controlled trial. PLos ONE 2014; 9(3):e91891. doi:10.1371/journal. pone.0091891.

54. Bachmann G, Korner P. Bleeding patterns associated with non-oral hormonal contraceptives: a review of the literature. Contraception. 2009;79:247-58.

55. Frishman GN. Evaluation and treatment of menorrhagia in an adolescent population. J Minim Invasive Gynecol. 2008; 15:682-8.

56. Guzick DS, Berga SL, Wing R, Winters SJ, Smith D. Endocrine consequences of weight loss in obese, hyperadrogenic, anovulatory women. Fertil Steril. 1994;61:598-604.

57. Lauren's Hope medical ID jewelry. Available at: https:// www.laurenshope.com. Retrieved December 24, 2015.

58. American Medical ID. Available at: http://www. americanmedical-id.com. Retrieved December 24, 2015.

59. Huguelet $P$, Buyers E, Lange-Liss J, Scott S. Treatment of acute abnormal uterine bleeding in adolescents: what are providers doing in various subspecialties? J Pediatr Adolesc Gynecol. 2015. doi:10.1016/j.jpag.2015. 